\title{
ON THE DANYSZ EFFECT.
}

\section{By SVANTE ARRHENIUS.}

. IN this Journal (vol. vir. p. 501) Mr J. A. Craw has recently published a very sharp criticism of ${ }^{1}$ my calculations based on experiments by Madsen and Walbum regarding the so-called Danysz Effect.

Before entering upon the objections of $\mathrm{Mr}$ Craw it appears advisable to recall some points in the development of this question. The effect found by Danysz ${ }^{2}$ in experiments with ricin and diphtheria-toxin in 1902 was demonstrated by von Dungern ${ }^{3}$ and Sachs ${ }^{4}$ for some other toxins and was by these authors considered inexplicable, from the point of view, taken by Madsen and myself, that the neutralisation of a poison by its antibody is a chemical process subject to the law of mass-action. To explain this effect von Dungern supposed the existence of a new substance called epitoxonoild in the diphtheria poison, which even before had been supposed by Ehrlich to contain some seven or eight different substances, by the presence of which Ehrlich tried to explain different phenomena observed by himself and his pupils. Sachs also participated in this opinion regarding the constitution of the poisons investigated by him.

As very few exact data were published regarding the said effect, and it was held by the Frankfort school that it was inexplicable from our standpoint, Madsen executed, with the assistance of Walbum, a great number of experiments regarding the behaviour of tetanolysin in this relation, and gave them to me for calculation. It is against this calculation that Mr Craw directed his criticism. In order to clear up the question it will be useful for the sake of comparison to give an example of a chemical reaction, analogous to the effect of Danysz, and well known in general chemistry.

1 Madsen and Arrhenius (1906), Meddelanden Nobel Instit. vol. I. No. 3.

2 Danysz (1902), Ann. de l'Inst. Pasteur, vol. xvi. p. 311.

3 von Dungern (1904), Deutsche med. Wochenschr. Nos. 8 and 9.

4 H. Sachs (1904), Centralbl. f. Bacteriol. xxxvi. Abt. I. 251.

Journ. of Hyg. vilI 
This example regards the chloracetic acid which has been investigated by Schwab in the laboratory of van 't Hoff. If a quantity of chloracetic acid is neutralised with an alkali, e.g. sodium hydrate in excess, a reaction takes place according to the formula:

$$
\mathrm{CH}_{2} \mathrm{ClCOONa}+\mathrm{NaOH}=\mathrm{CH}_{2} \mathrm{OHCOONa}+\mathrm{NaCl} \text {, }
$$

indicating the formation of glycolic acid from the chloracetic acid. The reaction goes on very slowly at room temperature, but proceeds at temperatures above $65^{\circ} \mathrm{C}$. We will therefore suppose that we work at this or higher temperatures.

The alkalinity of the mixture decreases, at first more rapidly, later on more slowly, and the rate of decrease is proportional to the quantity of free sodium hydrate (or better hydroxylions) and to the quantity of sodium chloracetate present. After a sufficient time (about two days at $100^{\circ} \mathrm{C}$.) the sodium hydrate is neutralised, if the chloracetate is present in excess. The limit quantity of neutralised sodium hydrate is therefore simply proportional to the quantity of sodium hydrate which is not used up for neutralising the chloracetic acid.

Suppose now that we have two solutions, the one containing two grammolecules of chloracetic acid and the other two grammolecules of sodium hydrate; if we mix them at once, two grammolecules of sodium chloracetate are formed, and thereafter no sensible reaction takes place. The solution is neutral. If on the other hand we divide the acid solution into two equal parts and mix the one of them with the alkaline solution and let the mixture stand at $100^{\circ} \mathrm{C}$. for some time and thereafter add the rest to the acid, the resultant mixture will be acid, and this the more, the longer time the first mixture has been held at $100^{\circ} \mathrm{C}$. After a sufficient time the first mixture will have reached its limit value of acidity, it will be neutral, so that the whole quantity of the second part of the acid will remain unneutralised. If we call the strength of the original two solutions 2 , then the acidity of their mixture made at once will be 0 , and the acidity of the fractionated mixture will increase with the time during which the first fraction has been held at $100^{\circ} \mathrm{C}$., and tend to a limit value, in this case 1 . If we had taken a solution of sodium hydrate containing more than one and less than two grammolecules, the limit value of the acidity of the resulting solution would have been proportional to the number of grammolecules diminished by one, which had been neutralised by the equivalent quantity of

1 Schwab, in Études de dynamique chimique, by van 't Hoff, 1883. 
chloracetic acid in the first fraction, or, in other words, proportional to the quantity of free alkali in the first fraction.

Evidently this phenomenon shows a very marked parallelism with the effect of Danysz. There the chloracetic acid is represented by the toxin, the alkali by the antitoxin, and the toxicity by the acidity. If we take equivalent quantities of toxin and antitoxin in two solutions and divide the toxin solution in equal parts, the quantity of free toxin required is greater if we mix the one part of the toxin with the antitoxin, and let it stand for a time and thereafter add the rest of the toxin, than if the total quantity of toxin is mixed simultaneously with the antitoxin. There is one difference, but only a quantitative one, namely that in a mixture of equivalent quantities of toxin and antitoxin there is always a certain quantity of free poison present, just as there is free boracic acid in a mixture of equivalent quantities of ammonia and boracic acid. In other words, the reaction between toxin and antitoxin is incomplete just as that between ammonia and boracic acid, whereas the reaction between alkali and chloracetic acid is said to be complete. But every chemist knows that this is not exactly true, since the sodium chloracetate is hydrolysed to a certain, although very slight, extent. If now in the first fraction there is free antitoxin (as is always the case), the limit value of the Danysz Effect is proportional to this quantity of free antitoxin, just as the limit value of the corresponding neutralising effect of the chloracetic acid is proportional to the quantity of free sodium hydrate. But as the proportionality for this later effect is only valid till the quantity of free sodium hydrate reaches a certain limit, the same will probably be true for the Danysz Effect, but this point has not as yet been investigated.

Now Mr Craw says that I am not entitled to suppose that the Danysz Effect tends to a certain limit with increasing time of reaction of the first fraction. If this were not true, we might suppose that we would obtain an infinite effect, i.e. an infinitely great toxicity of the mixture, if the time of reaction increased indefinitely. That would be just as right as to suppose that the acidity of the chloracetic acid mixture would increase to infinity with increasing time of reaction of the first fraction. It seems to me unnecessary to enter into a more detailed discussion of this point.

Further Mr Craw says that, as there is a certain quantity of free antitoxin in all experiments according to the law of mass-action, we must expect a Danysz Effect in all experiments, whereas these show no sensible effect, if the antitoxin in the first fraction does not exceed the 
quantity of toxin. I have only assumed that the effect is not sensible, i.e. does not exceed the errors of experiment in the said case. To show this proportionality in the most evident manner, I give a little table below, cited in our memoir p. 13, in which I have calculated the effect as proportional to the quantity of antitoxin present in the experiments with a constant quantity of toxin and varying quantities of antitoxin. The basis of the calculation is that 0.18 c.c. of antitoxin are equivalent to 1 c.c. of toxin and that the equilibrium constant is $K=0.131$ at $37^{\circ} \mathrm{C}$., as had been determined through other experiments on the neutralisation of toxin with antitoxin (cf. p. 5). In this manner I find :

\begin{tabular}{|c|c|c|c|}
\hline \multirow{2}{*}{\multicolumn{4}{|c|}{$\begin{array}{l}\text { Composition of the first fraction } \\
0.2 \text { c.c. antitoxin }+1 \text { c.c. toxin }\end{array}$}} \\
\hline & & & \\
\hline $0 \cdot 4$, & , & +1 & ", \\
\hline 0.6, & ", & +1 & ", \\
\hline 0.8, & ," & +1 & ", \\
\hline $1 \cdot 2$, & ," & +1 & ," \\
\hline
\end{tabular}

$\begin{array}{cl}\text { Quantity of free antitoxin } \\ \text { In per cent. } & \text { Total } \\ 30.3 & 0.0606 \text { c.c. } \\ 58.6 & 0.234 \\ 71.2 & 0.427 \\ 78.3 & 0.626 \\ 85.3 & 1.024\end{array}$

\begin{tabular}{cc}
\multicolumn{2}{c}{ Danysz } \\
Observed & Calculated \\
5 & $5 \cdot 7$ \\
23 & $22 \cdot 1$ \\
39 & $40 \cdot 9$ \\
60 & 59 \\
97 & $96 \cdot 4$
\end{tabular}

The agreement between the two last columns is excellent and far within the errors of observation, and it may well be concluded that this series of observations gives a "very strong support" to the correctness of Madsen's and my idea that the laws of mass-action are valid. Evidently the determination of the quantity of antitoxin, which is equivalent to 1 c.c. of toxin by means of these last experiments, gives precisely the same value as the direct determination. This corresponds to the possibility of calculating the quantity of free sodium hydrate present in the mixtures, used in Schwab's experiments, from the endvalue of the acidity as well as from the direct measurement of the neutralising quantity.

The effect of Danysz, which had been employed as an argument against the use of the laws of mass-action on the reactions between antibodies, has by this calculation given the most startling proof of the applicability of these laws. It should be remembered that the opponents of the use of these laws have still given no explanation at all of the Danysz Effect, especially of the experiments cited in our memoir.

Mr Craw asserts that the law of mass-action, which I have applied to these phenomena, gives an equation which should only be regarded as an interpolation formula, because it contains two constants which may be determined from the experiments. It may well be remembered that I have found this formula applicable in all the thirty-five different 
cases which I have treated in my "Immunochemistry "," and which are taken from all the different departments of immunity. On the other hand $\mathrm{Mr}$ Craw asserts with Mr Biltz, that the neutralisation phenomena of toxin with antitoxin are due to the "adsorption" of the toxin by the antitoxin. "If $m$ is the quantity of adsorbing matter, $x$ the adsorbed quantity of the dissolved substance, $c$ the concentration of this substance, after the adsorption process has reached its limit value, $\alpha$ and $p$ are constants," then, says Freundlich", "the following equation holds good:

$$
\frac{x}{m}=\alpha c^{p},
$$

where $p$ in nearly all cases investigated falls between $0 \cdot 1$ and $0 \cdot 4$."

It is possible to apply this formula, which, as well as that deduced from the law of mass-action, contains two constants $\alpha$ and $p$ which are determined from the experimental results, to the great material collected in my lectures on immunity. It may well be regarded as very peculiar that the seven authors enumerated by Mr Craw as adherents of the adsorption theory, have not used this opportunity of proving the correctness of their theoretical views. I have tried to make this examination in six of the best investigated cases of neutralisation of toxin with antitoxin and find that $p$ has no constant value. With tetanolysin for instance $p$ varies from 0.235 to 0.77 with a mean value of about $\frac{1}{3}$. If we calculate the data for tetanolysin with this mean value, we find the figures written below under $T_{\text {calc }}$, which ought to be compared with the values $T_{\text {calc }_{1}}$ found by application of the formula given for the mass-action and the directly observed values $\mathbf{T}_{\mathrm{obs}}$, giving

\begin{tabular}{|c|c|c|c|}
\hline$n$ & $\mathbf{T}_{\text {obs }}$ & $\mathrm{T}_{\text {calc }_{1}}$ & $\mathbf{T}_{\text {calc }}$ \\
\hline 0 & 100 & 100 & 100 \\
\hline $0 \cdot 05$ & 82 & 82 & 82 \\
\hline 0.1 & 70 & 66 & 66 \\
\hline $0 \cdot 15$ & 52 & 52 & 53 \\
\hline 0.2 & 36 & 38 & 42 \\
\hline 0.3 & 22 & 23 & 25 \\
\hline 0.4 & $14 \cdot 2$ & $13 \cdot 9$ & 16 \\
\hline 0.5 & $10 \cdot 1$ & $10 \cdot 4$ & $10 \cdot 0$ \\
\hline 0.7 & $6 \cdot 1$ & $6 \cdot 3$ & 4.5 \\
\hline $1 \cdot 0$ & $4 \cdot 0$ & $4 \cdot 0$ & 1.7 \\
\hline $1 \cdot 3$ & $2 \cdot 7$ & $2 \cdot 9$ & 0.8 \\
\hline $1 \cdot 6$ & $2 \cdot 0$ & $2 \cdot 5$ & 0.4 \\
\hline $2 \cdot 0$ & 1.8 & 1.9 & 0.2 \\
\hline
\end{tabular}

\footnotetext{
1 Immunochemie, übers. v. Finkelstein (Akad. Verlagggesellsch. Leipzig, 1907); Immunochemistry (The MacMillan Co., New York, 1907).

${ }^{2}$ H. Freundlich (1907), Zeitschr. f. Chemie u. Industrie der Kolloide, I. 325.
} 
the quantity of free tetanolysin after the addition of $n$ parts of antitetanolysin (cf. Immunochemie, p. 117, English ed. p. 178).

An analogous calculation is given below for the neutralisation of rennet. In this case we know the probable errors, which are written under $\Delta$ (cf. Immunochemie, p. 180, English ed. p. 275), $p=0.05$.

$\begin{array}{lcccc}n & \mathrm{~T}_{\text {obs }} & \mathrm{T}_{\text {calc }_{1}} & \mathrm{~T}_{\text {calc }_{2}} & \Delta \\ 0 & 100 & 100 & 100 & - \\ 0 \cdot 02 & 97 \cdot 4 & 97 \cdot 1 & 97 \cdot 0 & 0 \cdot 6 \\ 0 \cdot 05 & 92 \cdot 3 & 92 \cdot 6 & 92 \cdot 5 & 1 \cdot 4 \\ 0 \cdot 1 & 85 \cdot 9 & 85 \cdot 2 & 85 \cdot 1 & 1 \cdot 5 \\ 0 \cdot 2 & 70 \cdot 4 & 70 \cdot 6 & 70 \cdot 4 & 1 \cdot 8 \\ 0 \cdot 3 & 54 \cdot 3 & 56 \cdot 0 & 56 \cdot 1 & 1 \cdot 9 \\ 0 \cdot 4 & 42 \cdot 6 & 41 \cdot 8 & 42 \cdot 3 & 1 \cdot 3 \\ 0 \cdot 5 & 30 \cdot 2 & 28 \cdot 2 & 29 \cdot 2 & 1 \cdot 2 \\ 0 \cdot 6 & 16 \cdot 5 & 16 \cdot 3 & 17 \cdot 2 & 0 \cdot 4 \\ 0 \cdot 7 & 8 \cdot 2 & 8 \cdot 4 & 7 \cdot 4 & 0 \cdot 6 \\ 0 \cdot 8 & 4 \cdot 7 & 4 \cdot 7 & 1 \cdot 7 & 0 \cdot 3 \\ 0.9 & 2 \cdot 8 & 3 \cdot 1 & 0 \cdot 2 & 0 \cdot 2\end{array}$

The adsorption formula does not give nearly so good results as the mass-action formula, and the discrepancy between $T_{\text {calc }}$ and $T_{o b}$ is startling, especially for the higher values of $n$. There the difference between these two values exceeds the probable error ten times or more, which may be regarded as proving the impossibility of the adsorption hypothesis (cf. Immunochemie, p. 142, English ed. p. 216).

Now Mr Craw repeats the objections of the Frankfort school, that the Danysz Effect upsets the view of simple equilibrium which is adopted as the basis for my calculation. It may be noted that in the memoir to which I have referred, I have shown "that this disturbing action is without sensible influence at $20^{\circ}$, if the time of reaction does not exceed one or two hours, a condition to which we have adhered in our experiments." This may easily be verified with help of the figures given in the said memoir, and Mr Craw has not tried to raise an objection against those figures. That it is necessary to avoid using too long periods of reaction in working with tetanolysin was already known to Madsen and myself in 1900, when we carried out the determinations for our first memoir ${ }^{1}$ on this toxin. The tetanolysin weakens with time, but our cxperience showed us that this deterioration was negligible during the time occupied by our experiments on the Danysz Effect. Different preparations are very unlike in this respect, so that $\mathrm{Mr}$ Craw's observation that a $4 \%$ solution of tetanolysin lost $25 \%$ of its activity in one hour

1 Festskrift ved indvielsen af statens serum.institut, No. 3, Copenhagen, 1902. 
at $37^{\circ} \mathrm{C}$. may well be possible-perhaps the experimental error has contributed to the high figure.

Mr Craw is opposed to my treatment of the Danysz Effect as depending on a monomolecular process. This conclusion was based by me on the observation that the magnitude of the effect is independent of the concentration of the reacting substances, and not at all on the progress of the reaction with time. The experimental errors are in this latter case too great to permit a definite conclusion, but the experiments on the influence of concentration seem to me to be wholly convincing. $\mathrm{Mr}$ Craw seems to have overlooked these experiments. He calculates the figures on the time progress as if the process were bimolecular and finds the agreement with the observation "highly satisfactory." The mean difference between observed and calculated values is according to my calculation, assuming the process to be monomolecular, $1.8 \%$, and according to Mr Craw's calculation on the assumption that the process is bimolecular, $1 \cdot 6 \%$, so that the two calculations may be said to be of very nearly the same value. Mr Craw therefore might regard the hypothesis that the process is monomolecular as being "highly satisfactory." This supposition that the process is bimolecular seems to me to be incompatible with the experiments on the influence of concentration.

There is still a point of theoretical interest, on which Mr Craw lays great stress. He is of opinion that colloïds, among which he reckons the antitoxin, do not diffuse. If the antitoxins were diffusible they would exert an osmotic pressure, and then the laws of equilibria might be applied, as I have done'. Now Madsen and $\mathrm{I}^{2}$ showed that antitoxins diffuse in a weak solidified solution of gelatin $(5 \%)$, and even that the distribution of the antitoxin conforms to the general laws of diffusion, formulated by Stefan. Mr Craw says that our experiments do not show that antitoxin diffuses; the presence of the $5 \%$ of gelatin caused the apparent diffusion, but the phenomenon observed was really due to imbibition, which is supposed not to exert its influence in similar experiments of Mr Craw. I confess that I cannot understand Mr Craw's argument. The difference of our opinions seems of little importance since Herzog and Kasarnowski have found that colloïds in general are subject to the general laws of diffusion. Herzog gave a lecture on Kasarnowski's experiments at the meeting of the Bunsen-Gesellschaft in Hamburg and drew from them the following conclusion: "The values found indicate that the osmotic pressure is the driving force in the

1 Cf. Immunochemie, p. 19, English ed. p. 28.

2 Festskrift, No. 4, Copenhagen, 1902 ; Immunochemie, p. 16, English ed. p. 25. 
diffusion of the colloïds investigated ${ }^{1}$." Nernst and Biltz, who are cited by $\mathrm{Mr}$ Craw as holding the opinion that colloïds do not diffuse, were present and took part in the discussion after the lecture, but they raised no objection to the view that the diffusion of colloids is due to their osmotic pressure.

It is much to be regretted that the authors, who support the adsorption hypothesis, do not use it for calculation of the great number of observations collected by different observers, especially those of Madsen and his collaborators. They would thereby contribute much more to the clearing up of the ideas on the nature of the action of antitoxins than they have done by their general assertions.

1 Zeitschr. f. Elektrochemie, 13, 1907. 